\title{
Clinical impact of a pharmacist-led inpatient anticoagulation service: a review of the literature
}

This article was published in the following Dove Press journal:

Integrated Pharmacy Research and Practice

26 May 2016

Number of times this article has been viewed

\author{
Tiffany Lee \\ Erin Davis \\ Jason Kielly \\ School of Pharmacy, Memorial \\ University, St John's, NL, Canada
}

Correspondence:Tiffany Lee School of Pharmacy, Memorial University, 300 Prince Philip Drive, St John's,

NL AIB 3V6, Canada

Tel +l 7097778858

Fax +I 7097777044

Email tfahey@mun.ca
Background: Anticoagulant therapies provide management options for potentially life-threatening thromboembolic conditions. They also carry significant safety risks, requiring careful consideration of medication dose, close monitoring, and follow-up. Inpatients are particularly at risk, considering the widespread use of anticoagulants in hospitals. This has prompted the introduction of safety goals for anticoagulants in Canada and the USA, which recommend increased pharmacist involvement to reduce patient harm. The goal of this review is to evaluate the efficacy and safety of pharmacist-led inpatient anticoagulation services compared to usual or physician-managed care.

Methods: This narrative review includes articles identified through a literature search of PubMed, Embase, and International Pharmaceutical Abstracts databases, as well as hand searches of the references of relevant articles. Full publications of pharmacist-managed inpatient anticoagulation services were eligible if they were published in English and assessed clinical outcomes. Results: Twenty-six studies were included and further divided into two categories: 1) autonomous pharmacist-managed anticoagulation programs (PMAPs) and 2) pharmacist recommendation. Pharmacist management of heparin and warfarin appears to result in improvements in some surrogate outcomes (international normalized ratio [INR] stability and time in INR goal range), while results for others are mixed (time to therapeutic INR, length of stay, and activated partial thromboplastin time [aPTT] measures). There is also some indication that PMAPs may be associated with reduced patient mortality. When direct thrombin inhibitors are managed by pharmacists, there seems to be a shorter time to therapeutic aPTT and a greater percentage of time in the therapeutic range, as well as a decrease in the frequency of medication errors. Pharmacist recommendation services have generally resulted in a greater time in therapeutic INR range, greater INR stability, decreased length of stay, and reduced major drug interactions, with no significant differences in safety outcomes.

Conclusion: Pharmacist-led inpatient anticoagulation management seems to result in superior outcomes, as compared to usual or physician-managed care. This conclusion is limited by small, poorly designed studies lacking statistical power, focusing mainly on surrogate outcomes.

Keywords: hospital, clinical pharmacy, direct thrombin inhibitors, venous thromboembolism, warfarin, heparin

\section{Introduction}

Anticoagulants are complex therapies that are used in the treatment and prevention of thrombosis and can themselves result in significant morbidity and mortality. In the outpatient setting, pharmacist-managed anticoagulation has been shown to decrease bleeding and thromboembolic events, as well as increase the likelihood of a therapeutic 
international normalized ratio (INR) for patients on warfarin. ${ }^{1}$ The widespread use of anticoagulant therapies in the inpatient setting poses significant risks to hospitalized patients. Anticoagulants, including the new direct thrombin inhibitors (DTIs), have been included on the Institute of Safe Medication Practices ${ }^{2}$ list of high-alert medications.

In the past decade, national accrediting bodies in the USA and Canada have incorporated anticoagulant safety goals into their accreditation standards for hospitals. ${ }^{3,4}$ For example, the Joint Commission's National Patient Safety Goal NPSG.03.05.01 focuses specifically on reducing patient harm associated with the use of anticoagulant therapies. ${ }^{3}$ As a result, an increasing number of hospitals have implemented pharmacist-led inpatient anticoagulation services to improve the safety and efficacy of anticoagulant therapies.

In 2008, Donovan et $\mathrm{al}^{5}$ published a review of pharmacistmanaged anticoagulation services in the inpatient setting. More specifically, their review assessed the efficacy, financial impact, and community acceptance of pharmacy-managed anticoagulation. The authors concluded that efficacy outcomes associated with pharmacy-managed anticoagulation (ie, warfarin and heparin therapy) appear equal or superior to the outcomes with usual care. However, they highlight "two significant caveats" to their conclusion: 1) experimental design in the majority of studies was poor and 2) observance of guidelines and protocols by pharmacists may be the reason for apparent superiority in a number of studies evaluated. ${ }^{5}$

We identified an apparent surge of publications in the literature comparing pharmacist-led anticoagulation to usual medical care since 2008, warranting an updated review. The goal of this narrative review is to evaluate the efficacy and safety of pharmacist-led inpatient anticoagulation services compared to usual or physician-managed care.

\section{Literature search and methods}

Relevant articles were identified through a search of the National Center for Biotechnology Information PubMed database (1946 to May 2015), Ovid Embase (1980 to May 2015), and International Pharmaceutical Abstracts (1970 to May 2015). Our search terms included "pharmacist" and/or "pharmacy", "inpatient", "hospital", "anticoagulation", and/or "anticoagulant", combined with each of the following terms: "warfarin", "heparin", "novel anticoagulants", "target-specific anticoagulants", and "direct oral anticoagulants". We handsearched the references of all relevant studies to identify any papers not found in our initial search. Full publications of trials assessing clinically relevant outcomes of pharmacist-managed anticoagulation services compared to usual or physician-led care were eligible for inclusion. Articles were excluded if they were published in languages other than English, were quality assessment studies without a control group for comparison, and were based on technological interventions (eg, computerbased dosing programs), as well as if the articles were available only as abstracts. A total of 26 papers were included, divided into two categorizes based on the type of pharmacistmanaged anticoagulation service: 1) autonomous pharmacistmanaged anticoagulation programs (PMAPs) - those that examined pharmacist-managed inpatient anticoagulation programs in which the pharmacists provided autonomous patient care and 2) pharmacist recommendation - those that examined programs whereby the pharmacist made treatment recommendations but did not have the authority to provide independent care.

\section{Autonomous PMAPs}

Nineteen studies evaluating autonomous inpatient PMAPs versus usual or physician-managed care were included in our review (Table 1). The types of programs varied between pharmacist use of established anticoagulation dosing protocols/ nomograms and programs that allowed for anticoagulation management at the discretion of the pharmacist's clinical judgment. Medications managed by the PMAP in each study ranged from warfarin and heparin to DTIs.

\section{Warfarin}

Fourteen studies evaluated warfarin-based autonomous PMAPs. Overall, they suggest that pharmacists perform better than physicians in the management of patients receiving anticoagulants or that there was no difference. ${ }^{6-19}$ A number of efficacy outcomes, focusing on INR trends, and safety outcomes were evaluated. Efficacy outcomes included instances of supra-/subtherapeutic INR, time within therapeutic INR, average time to achieve therapeutic INR, and length of stay. Instances of bleeding, thromboembolic events, and drug-drug interactions were among the safety outcomes evaluated.

\section{Efficacy}

Several studies failed to show a difference between groups ${ }^{11,14}$ or saw a significant reduction in supra-/subtherapeutic INR $^{6-8}$ or a nonsignificant trend toward reduced supra-/ subtherapeutic INR ${ }^{10,13,15}$ when PMAPs were compared to anticoagulation management by a physician. Dawson et $\mathrm{al}^{6}$ conducted a prospective, nonrandomized trial with patients on cardiology, internal medicine, and family medicine 
Table I Summary of included trials

\begin{tabular}{|c|c|c|c|c|c|}
\hline Author (year) & Study design & Patient population & Medications & Sample size & $\begin{array}{l}\text { Statistically significant results } \\
\text { for pharmacist group }\end{array}$ \\
\hline \multicolumn{6}{|l|}{ PMAP } \\
\hline $\begin{array}{l}\text { Dawson et } a^{6} \\
(2011)\end{array}$ & $\begin{array}{l}\text { Prospective, } \\
\text { nonrandomized } \\
\text { trial }\end{array}$ & $\begin{array}{l}\text { Patients who received at } \\
\text { least one dose of warfarin } \\
\text { for any indication }\end{array}$ & Warfarin & $\begin{array}{l}\mathrm{P}=217 \text { (protocol); } \\
\mathrm{c}=293 \text { (physician dosing) }\end{array}$ & Fewer INR results $>5.0$ \\
\hline $\begin{array}{l}\text { To and Jackevicius }{ }^{26} \\
\text { (20II) }\end{array}$ & $\begin{array}{l}\text { Prospective/ } \\
\text { retrospective } \\
\text { cohort }\end{array}$ & $\begin{array}{l}\text { Patients with suspected } \\
\text { or documented HIT who } \\
\text { received a continuous } \\
\text { infusion of a DTI for at } \\
\text { least } 24 \text { hours }\end{array}$ & $\begin{array}{l}\text { Lepirudin, } \\
\text { argatroban }\end{array}$ & $\begin{array}{l}\mathrm{P}=98 \text { (protocol); } \\
\mathrm{c}=95 \text { (primary team; } \\
\text { preprotocol) }\end{array}$ & $\begin{array}{l}\text { Shorter time to achieve } \\
\text { therapeutic aPTT, greater } \\
\text { percentage of time in target } \\
\text { aPTT range, less TIMI major } \\
\text { bleeding }\end{array}$ \\
\hline Brice $^{8}(200 \mathrm{I})$ & $\begin{array}{l}\text { Prospective } \\
\text { cohort }\end{array}$ & $\begin{array}{l}\text { All warfarin patients on } \\
\text { general medicine, elderly } \\
\text { medicine, step-down CCU }\end{array}$ & Warfarin & $\begin{array}{l}P=67 \text { (pharmacist dosing); } \\
c=65 \text { (physician dosing) }\end{array}$ & $\begin{array}{l}\text { Less pseudoevents (INR } \geq 5 \\
\text { or } \leq \mathrm{I} .5 \text { ) }\end{array}$ \\
\hline $\begin{array}{l}\text { Damaske and } \\
\text { Baird }^{13}(2005)\end{array}$ & $\begin{array}{l}\text { Prospective } \\
\text { cohort }\end{array}$ & DVT/VTE, PE, AF, CVA & Warfarin & $\begin{array}{l}\mathrm{P}=29 \text { (protocol) } \\
\mathrm{c}=22 \text { (physician dosing) }\end{array}$ & None \\
\hline $\begin{array}{l}\text { Mamdani et al } \\
\text { (1999) }\end{array}$ & $\begin{array}{l}\text { Prospective } \\
\text { cohort }\end{array}$ & $\begin{array}{l}\text { Admitted for DVT/PE } \\
\text { and received IV heparin }\end{array}$ & $\begin{array}{l}\text { Heparin, } \\
\text { warfarin }\end{array}$ & $\begin{array}{l}\mathrm{P}=50 \text { (heparin weight-based } \\
\text { protocol; warfarin } \\
\text { dosing nomogram); } \\
\mathrm{c}=50 \text { (physician dosing) }\end{array}$ & $\begin{array}{l}\text { Less subtherapeutic aPTTs, } \\
\text { greater percentage of therapeutic } \\
\text { aPTT values, shorter time } \\
\text { between blood draws and } \\
\text { response to nontherapeutic } \\
\text { aPTT. Earlier warfarin start } \\
\text { and shorter LOS }\end{array}$ \\
\hline $\begin{array}{l}\text { Chenella et al }{ }^{17} \\
(1983)\end{array}$ & $\begin{array}{l}\text { Prospective } \\
\text { RCT }\end{array}$ & $\begin{array}{l}\text { Patients referred to the } \\
\text { anticoagulant service }\end{array}$ & $\begin{array}{l}\text { Heparin, } \\
\text { warfarin }\end{array}$ & $\begin{array}{l}\mathrm{P}=42 \text { (protocol); c =39 } \\
\text { (physician; protocol) }\end{array}$ & None \\
\hline $\begin{array}{l}\text { Cooper et } \mathrm{al}^{25} \\
(2012)\end{array}$ & $\begin{array}{l}\text { Retrospective } \\
\text { cohort }\end{array}$ & $\begin{array}{l}\text { Adult patients with } \\
\text { suspected HIT treated } \\
\text { with a DTI for }>24 \text { hours }\end{array}$ & $\begin{array}{l}\text { Argatroban, } \\
\text { bivalirudin }\end{array}$ & $\begin{array}{l}\mathrm{P}=25 \text { (protocol); } \mathrm{c}=25 \\
\text { (usual care, preprotocol) }\end{array}$ & $\begin{array}{l}\text { Achieved therapeutic aPTT } \\
\text { sooner and percent total time } \\
\text { at therapeutic aPTT was greater }\end{array}$ \\
\hline Airee et al" (2009) & $\begin{array}{l}\text { Retrospective } \\
\text { cohort }\end{array}$ & $\begin{array}{l}\mathrm{MI}, \mathrm{VTE}, \mathrm{AF} \text {, or CVA } \\
\text { new to warfarin with } \\
\text { goal INR range } 2-3\end{array}$ & Warfarin & $\begin{array}{l}\mathrm{P}=50 \text { (protocol); } \mathrm{c}=50 \\
\text { (physician dosing) }\end{array}$ & $\begin{array}{l}\text { Longer time to therapeutic INR } \\
\text { but less drug interactions }\end{array}$ \\
\hline $\begin{array}{l}\text { Chilipko and } \\
\text { Norwood }^{10}(2014)\end{array}$ & $\begin{array}{l}\text { Retrospective } \\
\text { cohort }\end{array}$ & $\begin{array}{l}\text { Receiving warfarin for } \\
3 \text { days consecutively } \\
\text { (excluding orthopedic } \\
\text { surgery) }\end{array}$ & Warfarin & $\begin{array}{l}\mathrm{P}=179 \text { (pharmacist } \\
\text { dosing) } \mathrm{c}=I 79 \\
\text { (physician dosing) }\end{array}$ & $\begin{array}{l}\text { Time within therapeutic INR } \\
\text { greater but longer LOS }\end{array}$ \\
\hline Saya et $\mathrm{al}^{21}(1985)$ & $\begin{array}{l}\text { Retrospective } \\
\text { cohort }\end{array}$ & $\begin{array}{l}\text { All medical-surgical } \\
\text { patients receiving } \\
\text { heparin by continuous } \\
\text { IV infusions }\end{array}$ & Heparin & $\begin{array}{l}\mathrm{P}=26 \text { (weight-based } \\
\text { protocol); } \mathrm{c}=62 \\
\text { (physician empiric dosing) }\end{array}$ & None \\
\hline Tschol et al ${ }^{7}(2003)$ & $\begin{array}{l}\text { Prospective/ } \\
\text { retrospective } \\
\text { cohort }\end{array}$ & Postcardiac valve surgery & Warfarin & $\begin{array}{l}\mathrm{P}=97 \text { (nomogram); } \\
\mathrm{c}=130 \text { (physician dosing) }\end{array}$ & Fewer days with INR $>5.0$ \\
\hline Rivey et al ${ }^{16}(1995)$ & $\begin{array}{l}\text { Prospective/ } \\
\text { retrospective cohort }\end{array}$ & Orthopedic surgery & Warfarin & $\begin{array}{l}P=|5| \text { (protocol); } \\
c=4 \mid \text { (physician dosing) }\end{array}$ & None \\
\hline Boddy $^{9}(200 \mathrm{I})$ & Prospective cohort & $\begin{array}{l}\text { Acute medical wards } \\
\text { (DVT, PE, AF, etc) }\end{array}$ & Warfarin & $\begin{array}{l}\mathrm{P}=74 \text { (protocol); } \\
\mathrm{c}=68 \text { (physician dosing) } \\
\mathrm{c}=64 \text { (physicians dosing } \\
\text { with protocol) }\end{array}$ & $\begin{array}{l}\text { Greater proportion of patients } \\
\text { within target INR }\end{array}$ \\
\hline $\begin{array}{l}\text { Schillig et al }{ }^{14} \\
(201 \mathrm{I})\end{array}$ & Cluster RCT & $\begin{array}{l}\text { All patients receiving } \\
\text { warfarin in two medical } \\
\text { and two cardiology units }\end{array}$ & Warfarin & $\begin{array}{l}\mathrm{P}=250 \text { (pharmacist dosing); } \\
\mathrm{c}=250 \text { (physician dosing) }\end{array}$ & $\begin{array}{l}\text { Greater compliance with } \\
\text { transition of care metric }\end{array}$ \\
\hline Lobo et $\mathrm{al}^{27}(2010)$ & $\begin{array}{l}\text { Prospective/ } \\
\text { retrospective } \\
\text { cohort }\end{array}$ & $\begin{array}{l}\text { Patients with } \\
\text { confirmed HIT }\end{array}$ & $\begin{array}{l}\text { Argatroban, } \\
\text { lepirudin }\end{array}$ & $\begin{array}{l}\mathrm{P}=17 \text { (revised protocol); } \\
\mathrm{c}=18 \text { (physician; protocol) }\end{array}$ & $\begin{array}{l}\text { Less dosing errors and } \\
\text { reexposure to heparin }\end{array}$ \\
\hline $\begin{array}{l}\text { Hosmane et al }{ }^{15} \\
(2010)\end{array}$ & Prospective cohort & Postcardiac surgery & Warfarin & $\begin{array}{l}P=46 \text { (pharmacist dosing); } \\
c=50 \text { (physician dosing) }\end{array}$ & None \\
\hline
\end{tabular}


Table I (Continued)

\begin{tabular}{|c|c|c|c|c|c|}
\hline Author (year) & Study design & Patient population & Medications & Sample size & $\begin{array}{l}\text { Statistically significant results } \\
\text { for pharmacist group }\end{array}$ \\
\hline Burns $^{12}(2004)$ & Prospective cohort & $\begin{array}{l}\text { All warfarin medical } \\
\text { patients in wards for } \\
\text { the elderly }\end{array}$ & Warfarin & $\begin{array}{l}\mathrm{P}=33 \text { (protocol) } \\
\mathrm{c}=33 \text { (protocol) }\end{array}$ & None \\
\hline $\begin{array}{l}\text { Bond and Raehl }{ }^{19} \\
\text { (2004) }\end{array}$ & $\begin{array}{l}\text { Retrospective } \\
\text { hospital database } \\
\text { review }\end{array}$ & $\begin{array}{l}\text { Medicare patients } \\
\text { receiving anticoagulation } \\
\text { in US hospitals }\end{array}$ & $\begin{array}{l}\text { Heparin }(h) \\
\text { warfarin }(w)\end{array}$ & $\begin{array}{l}\text { (h) } p=148,597 \\
\text { (h) } c=568,799 \\
\text { (w) } p=84,219 \\
\text { (w) } c=633,177\end{array}$ & $\begin{array}{l}\text { Lower mortality, reduced length } \\
\text { of stay, and fewer bleeding } \\
\text { complications }\end{array}$ \\
\hline $\begin{array}{l}\text { Pawloski and } \\
\text { Kersh }^{20} \text { (1992) }\end{array}$ & Prospective cohort & $\begin{array}{l}\text { Patients receiving } \\
\text { full-dose continuous } \\
\text { IV heparin therapy }\end{array}$ & Heparin & $\begin{array}{l}\text { Phase I: } p=29 \\
\text { (weight-based protocol); } \\
c=14 \text { (physician, } \pm \\
\text { weight-based protocol) } \\
\text { Phase II: } \\
\text { p =3I (weight-based } \\
\text { protocol); c = I4 (physician, } \\
\pm \text { weight-based protocol) }\end{array}$ & $\begin{array}{l}\text { Time to therapeutic aPTT was } \\
\text { shorter in pharmacist group }\end{array}$ \\
\hline \multicolumn{6}{|c|}{ Pharmacist recommendation } \\
\hline Ellis et $\mathrm{al}^{28}(1992)$ & $\begin{array}{l}\text { Prospective/ } \\
\text { retrospective } \\
\text { cohort }\end{array}$ & $\begin{array}{l}\text { Inpatients receiving } \\
\text { warfarin }\end{array}$ & Warfarin & $\begin{array}{l}\mathrm{P}=52 \text { (pharmacist } \\
\text { recommendation) } \\
c=97 \text { (physician dosing) }\end{array}$ & $\begin{array}{l}\text { Decrease in the frequency of } \\
\text { PT and PTT testing, greater PT } \\
\text { stability, and increased referrals } \\
\text { to the outpatient clinic }\end{array}$ \\
\hline Cronin et $\mathrm{al}^{34}$ (2009) & $\begin{array}{l}\text { Prospective/ } \\
\text { retrospective } \\
\text { cohort }\end{array}$ & Orthopedic surgery & Any & $\begin{array}{l}P=953(\text { protocol }) \\
c=I, 003 \text { (physician dosing) }\end{array}$ & None \\
\hline $\begin{array}{l}\text { Dager and Gulseth } \\
\text { (2000) }\end{array}$ & $\begin{array}{l}\text { Prospective/ } \\
\text { retrospective } \\
\text { cohort }\end{array}$ & $\begin{array}{l}\text { Inpatients with new } \\
\text { warfarin prescription }\end{array}$ & Warfarin & $\begin{array}{l}\mathrm{P}=60 \text { (pharmacist } \\
\text { recommendation) } \\
c=60 \text { (physician dosing) }\end{array}$ & $\begin{array}{l}\text { Decrease in the number of } \\
\text { days on warfarin, less days } \\
\text { with INR }>3.5 \text { or }>6 \text {, lower } \\
\text { percentage of patients with INR } \\
>3.5 \text { or }>6 \text {, and fewer patients } \\
\text { receiving medications with major } \\
\text { interactions with warfarin }\end{array}$ \\
\hline Bauer et $\mathrm{al}^{33}$ (2008) & Prospective cohort & $\begin{array}{l}\text { All inpatients, excluding } \\
\text { maternity, nursery, } \\
\text { pediatric, and psychiatry }\end{array}$ & Any & $\begin{array}{l}\mathrm{P}=3,876 \text { patient days } \\
\text { (protocol); } \mathrm{c}=4, \mathrm{I} 5 \mathrm{I} \text { patient } \\
\text { days (physician dosing) }\end{array}$ & $\begin{array}{l}\text { Increased percentage of } \\
\text { patients with VTE prophylaxis } \\
\text { and decreased percentage of } \\
\text { discharges with DVT }\end{array}$ \\
\hline $\begin{array}{l}\text { Biscup-Horn et } \mathrm{al}^{32} \\
\text { (2008) }\end{array}$ & $\begin{array}{l}\text { Retrospective } \\
\text { cohort }\end{array}$ & $\begin{array}{l}\text { Cardiac surgery } \\
\text { patients (CABG and } \\
\text { valve surgery) receiving } \\
\text { warfarin }\end{array}$ & Warfarin & $\begin{array}{l}P=152(\text { protocol }) \\
c=674 \text { (physician dosing) }\end{array}$ & $\begin{array}{l}\text { Decreased percentage of patients } \\
\text { with INR }>5 \text { and decreased } \\
\text { postsurgical LOS }\end{array}$ \\
\hline $\begin{array}{l}\text { Wong et } \mathrm{al}^{30} \\
(2010)\end{array}$ & Prospective cohort & $\begin{array}{l}\text { General medicine and } \\
\text { surgery: new start on } \\
\text { warfarin for DVT, PE, } \\
\text { and AF }\end{array}$ & Warfarin & $\begin{array}{l}P=\mid 44 \text { (protocol) } \\
c=26 \text { (physician dosing) }\end{array}$ & $\begin{array}{l}\text { Increase in percentage of INR } \\
\text { values in therapeutic range within } \\
5 \text { days, decreased percentage of } \\
\text { INR }>4 \text { and subtherapeutic INR } \\
\text { on discharge, decreased time } \\
\text { to therapeutic INR and time to } \\
\text { discharge }\end{array}$ \\
\hline $\begin{array}{l}\text { Thompson et } \mathrm{al}^{29} \\
(2012)\end{array}$ & $\begin{array}{l}\text { Retrospective } \\
\text { cohort }\end{array}$ & $\begin{array}{l}\text { Inpatients receiving } \\
\text { warfarin }\end{array}$ & Warfarin & $\begin{array}{l}\mathrm{P}=100 \text { (pharmacist } \\
\text { recommendation); } \\
c=100 \text { (physician dosing) }\end{array}$ & $\begin{array}{l}\text { Increased time in INR goal range } \\
\text { and decreased time to goal INR }\end{array}$ \\
\hline
\end{tabular}

Abbreviations: AF, atrial fibrillation; aPTT, activated partial thromboplastin time; c, control; CABG, coronary artery bypass graft; CCU, coronary care unit; CVA, cerebrovascular accident; DTI, direct thrombin inhibitor; DVT, deep vein thrombosis; h, heparin; HIT, heparin-induced thrombocytopenia; INR, international normalized ratio; IV, intravenous; LOS, length of stay; MI, myocardial infarction; p, pharmacist; PE, pulmonary embolism; PMAP, pharmacist-managed anticoagulation program; PT, prothrombin time; PTT, partial thromboplastin time; RCT, randomized controlled trial; TIMI, Thrombolysis in Myocardial Infarction criteria; VTE, venous thromboembolism; w, warfarin.

inpatient services. Patients were assigned to receive warfarin management through a detailed dosing protocol administered by pharmacists $(n=217)$ or through usual care by physicians $(n=293)$. The authors report that the use of the protocol by pharmacists resulted in significantly fewer INR results $>5$, as compared to usual care by physicians $(7.86 \%$ vs $1.85 \%$; $P=0.004) .{ }^{6}$ Tschol et $\mathrm{al}^{7}$ reported that, in patients undergoing valve replacement, pharmacist-managed patients had fewer 
days with INR $>4$ than a cohort of physician-managed patients ( $4 \%$ vs $10 \% ; P<0.001)$. This finding is particularly noteworthy, as the cardiologists and cardiothoracic surgeons responsible for postoperative care had considerable experience with anticoagulation management. ${ }^{5}$ A small study by Brice $^{8}$ compared pharmacist dosing of warfarin $(n=44)$ to physician dosing $(n=44)$ on a coronary care step-down unit, in a general medicine ward, and in a medical ward for the elderly. The pharmacist-dosed patients had a significantly reduced risk of a pseudoevent (defined as one or more INR results of $\leq 1.5$ or $\geq 5$ ) as compared to the physician group (relative risk [RR]: 0.14 ; 95\% confidence interval [CI]: $0.03-0.61){ }^{8}$

Pharmacists were also able to achieve a greater proportion of INR results in therapeutic range, as demonstrated in a study ${ }^{9}$ that evaluated warfarin administration before and after the introduction of a warfarin-prescribing guideline. Prior to guideline introduction, warfarin dosing by physicians was investigated over 4 weeks in four acute medical wards $(n=68)$. Prescribing guidelines were then circulated to the study physicians. Subsequently, in two of the wards, warfarin dosing was continued by physicians with the aid of the warfarin-prescribing guideline $(n=64)$, while in the other two wards, warfarin dosing, as per the guidelines, from Day 4 of treatment onward was the responsibility of the hematology pharmacist. Pharmacist management achieved significantly better INR control (proportion of INRs within target range) compared to either of the physician groups (58\% pharmacy vs $18 \%$ physicians with guidelines vs $15 \%$ physicians; $P<0.001) .{ }^{9}$

A number of studies compared the time spent within goal INR range for PMAPs versus physician management. ${ }^{7-12}$ Generally, the time spent in therapeutic range was higher in the pharmacy-managed groups $s^{7-10,12}$ or there was no difference between groups. ${ }^{11}$ Chilipko and Norwood ${ }^{10}$ recently conducted a retrospective chart review of patients followed by an inpatient anticoagulation management service to compare pharmacist-managed patients $(n=179)$ with those receiving standard of care through physician management $(n=179)$. For the primary outcome of mean time spent within goal INR range, pharmacist-managed patients spent significantly greater time within goal range as compared to the physician-managed group (2.84 days vs 2.20 days; $P=0.017) .{ }^{10}$ Similarly, the study by Brice et $\mathrm{al}^{8}$ described above found that the percentage of patients in his pharmacydosed group who were newly anticoagulated (100\% vs $72 \%$; $P=0.025)$ and patients with a target INR of $2.5(100 \%$ vs $66 \% ; P=0.017$ ) were maintained for a significantly longer period of time within 0.75 INR units of the target INR.
However, differences were not significant when all study patients were included in the analysis. ${ }^{8}$

A nonsignificant trend toward an improved time to therapeutic INR for PMAPs was also noted by a number of studies, ${ }^{9,12}$ while other studies noted no difference between groups. ${ }^{7,10,13}$ In contrast to these findings, Airee et $\mathrm{al}^{11}$ conducted a retrospective chart review, which suggested that the time to therapeutic INR was significantly lower (4.3 days vs 5.3 days; $P=0.006$ ) in patients managed through usual care by a physician $(n=50)$ as compared to patients managed by a pharmacists' anticoagulation management service protocol $(n=50)$. The authors note that these findings may be explained by a tendency toward greater use of loading doses in the physician group. ${ }^{11}$

Finally, a number of studies $6,7,10-12,14,15,18$ compared the average length of stay for patients under the care of PMAPs to those cared for by physicians. Again, the majority of studies suggest no difference between groups $s^{6,7,11,12}$ or a nonsignificant trend toward decreased length of stay among patients managed by pharmacists. ${ }^{15,18}$ Two studies ${ }^{10,14}$ suggested that physician-managed patients had a significantly shorter length of stay compared to pharmacist-managed patients.

The largest study ${ }^{19}$ by far to compare PMAPs with usual care analyzed data, obtained via a mailed questionnaire, from the 1995 National Clinical Pharmacy Services and Medicare database for hospitals, which included analysis of 717,396 Medicare patients treated in 955 hospitals for conditions requiring anticoagulant therapy. Hospitals with pharmacist-managed warfarin therapy had lower mortality (6.7\% vs $7.1 \%$ ) and reduced hospital length of stay ( 8.0 days vs 8.5 days) compared to hospitals without pharmacistmanaged care (all comparisons $P<0.0001) .{ }^{19}$ Although the benefits reported by this retrospective analysis are significant, there are a number of limitations to consider. The study shows associations between major health outcomes (death rate and length of stay) and PMAPs, but as with most of the other articles included in this review, the study design does not allow us to determine direct relationships or causality. The majority of hospitals eligible for inclusion did not respond to the survey ( $30 \%$ response rate) and the PMAPs comprised only $10 \%$ of the patients and hospitals analyzed. ${ }^{19}$ Furthermore, hospitals were not categorized (eg, large vs small, academic vs nonacademic), and other potential confounding factors (eg, patient demographics, availability of specialist physicians) were not discussed. ${ }^{5}$

\section{Safety}

While the predominant goal of the identified studies was to evaluate the efficacy of inpatient PMAPs, a number 
of studies also evaluated the impact of such programs on safety outcomes. ${ }^{7,10-14,16-18}$ Safety outcomes such as rates of bleeding, thromboembolic events, and warfarin-drug interactions were evaluated. Most studies reported a nonsignificant trend toward fewer bleeding episodes ${ }^{11,13,17}$ or no differences between groups. . $^{70,12,14,16,17}$ No study noted differences for thromboembolic events. Unfortunately, the majority of studies were small and not designed to detect differences between groups for a bleeding or thromboembolic event. The definitions of bleeding and thromboembolic events varied from study to study, ranging from no specific definition to clearly defined. Bond and Raeh ${ }^{19}$ noted in their large retrospective review that hospitals with PMAPs had significantly fewer bleeding complications versus hospitals without PMAPs (8.4\% vs $9.2 \%, P<0.0001)$.

\section{Heparin}

Five studies ${ }^{18-21}$ that evaluated outcomes in patients receiving intravenous (IV) heparin therapy were included in our review. Different study designs were used in each, and outcomes assessed were variable. Each study demonstrated some benefit for pharmacist-led heparin therapy. Of note, three ${ }^{17-19}$ of the studies also evaluated the use of warfarin. Outcomes pertaining to the use of heparin are discussed here.

\section{Efficacy}

The ability of pharmacists to successfully dose heparin (and warfarin) according to protocol was demonstrated by Chenella et $\mathrm{al}^{17}>3$ decades ago. Eighty-one patients referred to the anticoagulant service were randomized to the pharmacist-prescriber $(n=42)$ or physician-prescriber $(n=39)$ groups. All prescribers were blinded to patient randomization and independently performed daily dose adjustments and monitoring for both patient groups. However, the prescriber had to be informed of the anticoagulant dose received on the previous day when making dosage recommendations and, as such, true prescriber blinding was not possible. The authors reported no significant difference between groups in any outcome assessed, including the overall mean dose of heparin prescribed or the mean values for heparin dose and prothrombin time in the first 24 hours. ${ }^{17}$
The majority of studies included here compared the time to therapeutic activated partial thromboplastin time (aPTT) for PMAPs versus usual care or physician management (Table 2). ${ }^{18,20,21}$ Results are mixed, with one study ${ }^{18}$ reporting no difference between groups, another ${ }^{21}$ reporting results that showed a favorable trend for pharmacist-directed dosing, and the third ${ }^{20}$ noted a statistically significant difference between groups. It is important to highlight that pharmacist-led dosing of heparin achieved therapeutic aPTT within 24 hours in all three studies, a critical end point for the prevention of recurrent thrombosis. ${ }^{22,23}$

In addition to finding no difference in the time to therapeutic aPTT, Mamdani et al ${ }^{18}$ report no significant difference between the pharmacist-managed and usual care groups for their primary end point: the percentage of patients who surpassed a therapeutic aPTT of 48 seconds after the first dose of heparin ( $84 \%$ vs $78 \% ; P=0.44)$. However, the authors did find a significantly greater percentage of therapeutic aPTT values $(47.75 \%$ vs $41.5 \% ; P=0.05)$ and significantly less subtherapeutic aPTT values in the pharmacist-managed group ( $15.8 \%$ vs $21.3 \%$; $P=0.03)$, with no difference reported in terms of supratherapeutic aPTT values. ${ }^{18}$ Two important variables that may have weakened the difference between groups include poor pharmacist adherence to the heparin protocol and improved physician prescribing as a result of increased protocol awareness and use. ${ }^{18}$

Similar to the findings discussed in the previous section on "Warfarin" regarding pharmacist-managed warfarin therapy, Bond and Raehl ${ }^{19}$ report that hospitals with pharmacist-managed heparin therapy had a lower rate of mortality compared to hospitals without such services $(6.37 \%$ vs $7.19 \% ; P<0.0001) .{ }^{19}$ In addition, two studies ${ }^{18,19}$ found that heparin management by PMAPs reduced mean length of stay by 1-2 days.

Although each study discussed here demonstrated some benefit of pharmacist-managed heparin therapy, the inconsistent use of heparin-dosing protocols among comparison groups make the results difficult to compare across trials. Three studies ${ }^{18,20,21}$ evaluated pharmacist-managed heparin therapy using a weight-based dosing protocol compared to physician-managed therapy using empiric dosing or a

Table 2 Intravenous heparin therapy: time (hours) to achieve therapeutic aPTT

\begin{tabular}{llll}
\hline Author (year) & Pharmacist care (PMAP) & Usual care & P-value \\
\hline Mamdani et al ${ }^{18}(1999)$ & 23.6 & 25.3 & 0.14 \\
Saya et al ${ }^{21}(1985)$ & 22.9 & 35 & Statistical analysis not performed \\
Pawloski and Kersh ${ }^{20}(1992)$ & 9.32 & 31.64 & $<0.001$ \\
\hline
\end{tabular}

Abbreviations: aPTT, activated partial thromboplastin time; PMAP, pharmacist-managed anticoagulation program. 
standard care nomogram (also referred to as traditional dosing). It is difficult to interpret whether these results were due directly to pharmacist involvement or to the use of a more effective protocol, as one randomized controlled trial demonstrated the apparent superiority of weight-based dosing compared to a standard care nomogram. ${ }^{24}$ Chenella et al ${ }^{17}$ compared groups who used the same established protocol (protocol type not specified) and found no significant difference in the mean dose of heparin prescribed or the mean values for PTT.

\section{Safety}

Bond and Raehl ${ }^{19}$ also reported improved safety in hospitals with pharmacist-managed heparin therapy. Hospitals with pharmacist-managed heparin therapy had a lower rate of bleeding complications $(8.84 \%$ vs $9.12 \% ; P=0.0009)$ compared to hospitals without pharmacist management. ${ }^{19}$ However, it is important to consider the limitations of the study design, as discussed previously, when assessing direct relationships and improvements in safety.

Two additional studies ${ }^{17,18}$ reported instances of bleeding. In one study, ${ }^{17}$ four patients in the pharmacist-managed group experienced minor bleeding, while no patients experienced bleeding in the physician-managed group; no statistical analysis was performed for this outcome. No statically significant difference was noted between groups in terms of minor bleeding in the second study. ${ }^{18}$ Four percent of patients receiving usual care experienced major bleeding compared to none in the pharmacist-managed group; the authors report that one patient in the pharmacist-managed group died as a result of a pulmonary embolism. ${ }^{18}$

\section{Direct thrombin inhibitors}

We identified three studies ${ }^{25-27}$ that evaluated clinical outcomes in patients with heparin-induced thrombocytopenia (HIT) treated with DTIs. Each study compared outcomes before and after the implementation of a pharmacist-led anticoagulation service. A similar service design was described by the authors of each study; much like the heparin studies, an institution approved protocol was used by the pharmacists who provided dosing and monitoring of DTIs in all three studies.

\section{Efficacy}

Two studies ${ }^{25,26}$ reported a statistically significant reduction in time to therapeutic aPTT and increase in percentage of time in therapeutic aPTT range between patients receiving pharmacist care and those who received usual care. Both studies reported a reduction in time to aPPT by $>50 \%$ (Table 3) and an absolute increase in the percentage of time in the therapeutic aPTT range of $10 \%-20 \%$ (Table 4 ). One study $^{25}$ evaluated the use of argatroban and bivalirudin, whereas the other ${ }^{26}$ evaluated the use of argatroban and lepirudin. Despite these benefits, Cooper et $\mathrm{al}^{25}$ reported no statistically significant difference between groups in terms of length of hospital stay.

Lobo et $\mathrm{al}^{27}$ were the first to publish a pre-/postintervention study evaluating pharmacist-led management of HIT using DTIs. However, study design and outcomes measured were different from the two studies discussed earlier. The authors first conducted a baseline study to evaluate the efficacy and safety of their newly developed DTI protocol. The intervention group consisted of physicians who were encouraged to use the protocol but not mandated to do so, while the comparison group consisted of physicians who did not use the protocol. Results from the baseline study showed no statistically significant difference between the groups in terms of rate of venous thromboembolism (VTE), amputation, or death. These findings prompted the institution to revise the DTI protocol; modifications were made to the dosing algorithms for both argatroban and lepirudin. Thereafter, the pharmacist managed all patients with HIT using the revised DTI protocol. A follow-up study was conducted, which compared patient outcomes between the pharmacist-managed group using the revised DTI protocol and the physician group who used the original DTI protocol in the baseline study. This design is a major limitation of the study, as the groups compared were using different DTI dosing algorithms, making it difficult to determine if the benefit seen was related to the new protocol or the pharmacist involvement. The authors did report a statistically significant decrease in the frequency of incorrect initial and bolus dosing of the DTIs (baseline group $=38 \%$; pharmacist-managed group $=9 \% ; P<0.05) .{ }^{27}$

\section{Safety}

Cooper et $\mathrm{al}^{25}$ reported no difference between the pre- and postimplementation groups in terms of frequency of major and minor bleeding, new thrombosis, or mortality. However,

Table 3 DTI therapy: time (hours) to therapeutic aPTT

\begin{tabular}{llll}
\hline Author (year) & $\begin{array}{l}\text { Pharmacist care } \\
\text { (PMAP) }\end{array}$ & Usual care & P-value \\
\left.\hline${\text { Cooper et } \mathrm{al}^{25}(2012)}^{20}\right)$ & 3.4 & 7.7 & 0.009 \\
To and Jackevicius $^{26}(20 \mathrm{II})$ & 6.4 & 18.9 & $<0.00 \mathrm{I}$ \\
\hline
\end{tabular}

Abbreviations: aPTT, activated partial thromboplastin time; DTI, direct thrombin inhibitor; PMAP, pharmacist-managed anticoagulation program. 
Table 4 DTI therapy: percentage of time in therapeutic aPTT

\begin{tabular}{llll}
\hline Author (year) & $\begin{array}{l}\text { Pharmacist care } \\
\text { (PMAP) }\end{array}$ & Usual care & P-value \\
\hline Cooper et $\mathrm{al}^{25}(2012)$ & 93 & $8 \mathrm{I}$ & $0.00 \mathrm{I}$ \\
To and Jackevicius $^{26}(20 \mathrm{II})$ & 84.7 & 64.4 & $<0.00 \mathrm{I}$ \\
\hline
\end{tabular}

Abbreviations: aPTT, activated partial thromboplastin time; DTI, direct thrombin inhibitor; PMAP, pharmacist-managed anticoagulation program.

this study was small $(\mathrm{n}=50)$ and not powered to assess safety outcomes. The authors did note a significant decline in the frequency of medication errors postimplementation of their pharmacist-led, collaborative drug therapy management program (preimplementation cohort $=10 \%$; postimplementation cohort $=3 \% ; P=0.05) .{ }^{25}$

To and Jackevicius ${ }^{26}$ evaluated bleeding using the Thrombolysis in Myocardial Infarction (TIMI) and Global Use of Strategies to Open Occluded Coronary Arteries (GUSTO) criteria. A greater number of patients experienced a TIMI major in the control group (ie, preimplementation of the pharmacist-managed anticoagulation service) compared to the pharmacist-managed group (eight patients vs three patients; $P=0.006)$. However, no difference was reported in terms of TIMI minor or GUSTO major or minor bleeding. ${ }^{26}$

In the follow-up study performed by Lobo et $\mathrm{al},{ }^{27}$ the authors report no significant difference in the rates of major or minor bleeding. However, dosing errors ( $9 \%$ vs $38 \%$ ) and heparin reexposure (6\% vs 39\%) were significantly less frequent in the pharmacist-managed revised protocol group compared to the physician-managed baseline protocol group. ${ }^{27}$

\section{Pharmacist recommendation}

The majority of literature currently available for inpatient, pharmacist-led anticoagulation services involves pharmacists with the authority to manage anticoagulation, adjust doses, and order laboratory tests. There is a smaller body of evidence representing consultant services, with pharmacists making dosing recommendations to primary health care providers who can then either accept or reject those recommendations (Table 1). This type of service may be more accessible to those who work in areas where pharmacist prescribing is not yet accepted practice.

\section{Warfarin}

Five studies ${ }^{28-32}$ that specifically measured the impact of a pharmacist recommendation service for warfarin were found. All five studies, published over a 20 -year period, demonstrate some benefit for pharmacist-led warfarin interventions, although they vary in size, design, and the clinical outcomes measured.

\section{Efficacy}

Ellis et $\mathrm{al}^{28}$ published the first study on the subject in 1992, discussing their unsolicited consultation to all inpatients receiving warfarin $(n=56)$ in comparison to usual physician care in a historical cohort $(\mathrm{n}=101)$. In comparison to physician-managed care, the pharmacist consultation service resulted in a small decrease in the frequency of monitoring of prothrombin time and partial thromboplastin time, but it showed a large but imprecise impact on referrals to the outpatient clinic (odds ratio: $12.2 ; 95 \%$ CI: 2.35-63.81). ${ }^{28}$ Since the publication of this study, there have been significant changes in monitoring of warfarin with the introduction of the INR, and several additional medications are now available for anticoagulation.

Among the more recent studies, the results are mixed. Thompson et $\mathrm{al}^{29}$ studied the impact of pharmacists and pharmacy students providing warfarin-dosing recommendations and patient education in an inpatient setting and found that, compared to usual care by physicians $(n=100)$, pharmacy involvement $(n=100)$ resulted in the INR being in the goal range for an increased time period $(50 \%$ vs $29 \%$; $P=0.0001)$ and decrease in the time to therapeutic INR (4.1 days vs 5.2 days for new users and 2.5 days vs 4.3 days for current users). Wong et $\mathrm{al}^{30}$ observed similar results when they studied pharmacists providing dosing recommendations and monitoring, after the initial warfarin dose was chosen by the physician. They saw a greater proportion of INRs in the therapeutic range within the first 5 days ( $88 \%$ vs $38 \%$; $P<0.001)$ and a shorter time to therapeutic INR (3.9 days vs 6.5 days; $P<0.001) .{ }^{30}$ In contrast, a study by Dager and Gulseth $^{31}$ showed no difference in time to therapeutic INR between physician-directed dosing $(n=60)$ and a pharmacistsurveillance dosing program $(n=60)$.

Two studies ${ }^{30,32}$ assessed length of stay, and both found that a pharmacist recommendation service reduced mean length of stay by 2-3 days. In their 2010 study, Wong et $\mathrm{al}^{30}$ noted that the pharmacist-managed cohort of patients $(n=144)$ had a mean time to discharge of 7.7 days compared to 11 days in the baseline cohort of patients $(\mathrm{n}=26)$ receiving usual care. A 2.3-day reduction in length of stay (13.9 days vs 11.6 days) was seen between the pre-anticoagulation monitoring service (AMS) $(n=674)$ and post-AMS $(n=152)$ groups in cardiac patients in a retrospective study. ${ }^{32}$ The AMS consisted of a physician and a pharmacist using a standardized protocol providing daily consultation on dose selection and monitoring. ${ }^{32}$

Three studies ${ }^{30-32}$ demonstrated that pharmacists were able to significantly improve the stability of inpatient INRs. The incidence of INRs $>5$ decreased from $13.4 \%$ to $7.2 \%$ 
$(P=0.036)$ with the implementation of a multidisciplinary AMS in one study. ${ }^{31}$ Wong et $\mathrm{al}^{30}$ showed a drop from $27 \%$ to $2 \%(P<0.001)$ for INRs $>4$ during warfarin titration and decreased subtherapeutic INRs on discharge. Finally, Dager and Gulseth ${ }^{31}$ saw a decrease in patients with INR $>3.5$ $(62 \%$ to $27 \% ; P<0.002)$ and in patients with INR $>6(33 \%$ to $3 \% ; P<0.001)$.

The pharmacist intervention by Dager and Gulseth ${ }^{31}$ also resulted in a significant decrease in patients receiving drugs with major interactions with warfarin ( $\operatorname{six}$ vs $13 ; P=0.02$ ), while Thompson et $\mathrm{al}^{29}$ did not show a statistically significant reduction in drug interactions with the introduction of pharmacist monitoring (68/100 patients) compared with traditional monitoring (57/100 patients).

A significant missing element in almost all of these studies is the compliance of physicians with pharmacist recommendations. Without the rate of acceptance of pharmacist recommendations, it is difficult to judge the impact of the pharmacist involvement on the results seen in these trials.

\section{Safety}

No difference was seen in bleeding, or thrombosis rates, between patients receiving pharmacist-recommended doses and those receiving traditional care, although sample sizes of the studies were small and none of the studies were powered to detect differences in the rates of adverse effects (Tables 5 and 6). ${ }^{28,31,32}$ Biscup-Horn et $\mathrm{al}^{32}$ noted that there was no difference in the proportion of patients receiving vitamin $\mathrm{K}$ in the pre- and postimplementation groups $(10.1 \%$ vs $10.5 \%$; $P=0.87$ ).

\section{VTE risk assessment services Efficacy}

Bauer et $\mathrm{al}^{33}$ reported the success of a pharmacist-led program designed to assess VTE risk and to recommend prophylaxis for inpatients. The clinical pharmacists assessed all new admissions (except maternity, nursery, pediatrics, and psychiatry) and completed a VTE risk assessment using a standardized tracking sheet. A $3^{\prime \prime} \times 5^{\prime \prime}$ sticker was placed in the "progress notes" section of the patient's medical record, which alerted physicians to known risk factors and VTE risk

Table 5 Warfarin therapy: documented or major bleeding

\begin{tabular}{llll}
\hline Author (year) & $\begin{array}{l}\text { Pharmacist care } \\
\text { (recommendation) }\end{array}$ & Usual care & P-value \\
\hline Dager and Gulseth $\left.^{31}(2000)\right)$ & $10 \%$ & $2 \%$ & 0.11 \\
Ellis et al $^{28}(1992)$ & $2 \%$ & $0 \%$ & 0.42 \\
Biscup-Horn et al $^{32}(2008)$ & $1.3 \%$ & $3.1 \%$ & 0.22 \\
\hline
\end{tabular}

Table 6 Warfarin therapy: recurrence of thrombosis

\begin{tabular}{|c|c|c|c|}
\hline Author (year) & $\begin{array}{l}\text { Pharmacist care } \\
\text { (recommendation) }\end{array}$ & Usual care & $P$-value \\
\hline Ellis et $\mathrm{al}^{28}(1992)$ & $3.1 \%$ & $3.8 \%$ & 0.57 \\
\hline Biscup-Horn et al $^{32}$ (2008) & $3.9 \%$ & $3.4 \%$ & 0.75 \\
\hline
\end{tabular}

level. For patients with the highest risk $(>20 \%$ estimated VTE risk), the pharmacists also provided recommendations for VTE prophylaxis, which the primary care provider was able to accept or reject. Despite a low (31\%) acceptance rate for recommendations, the pharmacy-led intervention demonstrated statistically and clinically significant benefits compared to a retrospective cohort from the period before program implementation. VTE prophylaxis rates increased from $19.5 \%$ to $60.2 \%$, while VTE rates decreased from $1.1 \%$ of discharged patients to $0.1 \%$. Barriers encountered during the implementation of this program included inconsistency among pharmacists in interpreting and identifying VTE risk factors, as well as physician concern regarding increased liability. ${ }^{33} \mathrm{~A}$ limitation of this study is the baseline reference sample, from 16 months prior to the implementation of this program. A standardized VTE prophylaxis order form was created and implemented between the baseline and pharmacy program samples introducing a confounding intervention, and some of the improvement noted in this study was probably due to the implementation of the order form. ${ }^{33}$ While the estimation of the efficacy of the pharmacy-led intervention may be imprecise, it does represent a clinically meaningful improvement in important patient outcomes.

Similarly, Cronin et a $l^{34}$ noted a reduction in overall VTE and pulmonary embolism (PE) rates with the implementation of a multidisciplinary, pharmacy-led, thromboprophylaxis program in orthopedic surgery patients. The intervention consisted of a thromboprophylaxis risk factor assessment-andprescriber order sheet, as well as education regarding protocol changes to discourage the use of warfarin monotherapy as this had been specifically noted to result in higher VTE rates at this institution. The clinical pharmacist was responsible for providing education about published guidelines, the risk factor assessment-and-prescriber order sheet, and protocol changes for prophylaxis. Daily chart reviews and twiceweekly patient care rounds with the orthopedic team ensured implementation of the risk assessment-and-order form. The pharmacist also managed the timing of low-molecular-weight heparin initiation after the removal of epidural catheters in cooperation with orthopedic physician assistants, surgical nurses, and anesthesiologists. Compared with rates in 
953 patients before implementation of the initiative, any VTE was reduced by $48 \%$ and $\mathrm{PE}$ was reduced by $57 \%$ in 1,003 patients undergoing total joint replacement procedures. ${ }^{34}$ A significant limitation in this study is the lack of statistical comparison between the before- and after-implementation event rates. The number of VTE and PE were small (44 VTE before implementation vs 24 VTE after, and nine PE before vs four after). ${ }^{34}$ In addition, the role of the pharmacist in the management of anticoagulation, the choice of agent, dosing, and monitoring is not clearly described. Whether the apparently beneficial result of this intervention is due to the blanket recommendation to reduce the use of warfarin for monotherapy or due to some intervention on the part of the pharmacist remains unclear. The compliance rate of physicians with pharmacist recommendations was not reported.

\section{Safety}

Bauer et $\mathrm{al}^{33}$ saw no cases of bleeding or HIT in their 1-month safety review of their pharmacist-led VTE risk assessment program, while Cronin et $\mathrm{al}^{34}$ do not comment on safety.

\section{Conclusion}

Thromboprophylaxis is often underused and inappropriately prescribed, despite the existence of evidenced-based guidelines. ${ }^{1}$ Preventable thromboembolic events represent an unnecessary clinical and economic burden, and there is increasing recognition of the need to optimize current care. ${ }^{1}$ Pharmacists are uniquely positioned to improve patient safety and play an important role in the dosing, monitoring, and education of anticoagulation therapy. An increasing number of hospitals have begun to implement PMAPs in an effort to improve efficacy and safety, and the body of literature supporting inpatient PMAPs continues to grow.

The literature reviewed indicates apparent benefits of inpatient PMAPs, with studies generally suggesting either superior outcomes when compared to usual or physicianmanaged care or no differences between groups. However, it is important to note that this study is limited by design as a narrative review, and although we had a rigorous search strategy, there may be relevant papers that were not identified or included. In addition, there are a number of limitations to the available evidence. First, a majority of the studies were of poor quality and not designed to determine direct relationships or causality. Most of the studies are retrospective in nature, typically in the form of a historical cohort. Some of the reference/ control groups for these studies are from as much as 3 years before the intervention groups. The potential exists for other changes to have influenced the benefit seen over this time period, such as institutional education programs, addition of new drugs to the market, new iterations of guidelines, and so on. Some studies lacked appropriate statistical analysis, while a number of studies had small sample sizes, making it difficult to show statistically significant differences between groups for rare outcomes such as bleeding and recurrence of thrombosis. The patient populations varied among studies (eg, elderly patients, postvalve replacement surgery patients, and orthopedic surgery patients), making comparison of results for interpretation difficult. Some studies had uneven group numbers, with many more patients in one arm of the study compared to the other, potentially allowing for less-common outcomes to be missed in the smaller group. Furthermore, the studies often focused on different end points given the nature of the service (ie, postoperative studies evaluated bleeding vs studies that focused on transition of care metrics). The larger comparative studies also possessed a number of the same flaws. Second, the benefit seen with pharmacist-managed care may be a result of guideline and protocol adherence. The majority of studies did not control for dosing by physicians, so it is difficult to interpret whether the results were due directly to the pharmacist involvement or to the pharmacists' use of protocols. These findings are consistent with those of Donovan et $\mathrm{al}^{5}$ in their 2008 review.

Pharmacist-led inpatient anticoagulation appears to enhance the quality of patient care, despite the limitations of the current literature. Larger, randomized prospective studies are needed to allow for more definitive conclusions.

\section{Acknowledgments}

The authors thank Dr Stephanie Young, Associate Professor, School of Pharmacy, Memorial University and Alison Farrell, Public Service Librarian, Health Sciences Library, Memorial University, for their assistance with the literature search for this review paper.

\section{Disclosure}

The authors report no conflicts of interest in this work.

\section{References}

1. Dobesh PP, Trujillo TC, Finks SW. Role of the pharmacist in achieving performance measures to improve the prevention and treatment of venous thromboembolism. Pharmacotherapy. 2013;33(6):650-664.

2. The Institute for Safe Medication Practices [webpage on the Internet]. List of High Alert Medications in Acute Care Settings. Available from: https://www.ismp.org/tools/highalertmedications.pdf. Accessed July 27, 2015.

3. The Joint Commission [webpage on the Internet]. Hospital Accreditation Program: National Patient Safety Goals, Effective January 1, 2015. Available from: http://www.jointcommission.org/assets/1/6/2015_NPSG_HAP. pdf. Accessed July 27, 2015. 
4. Accreditation Canada. Medication Management Standards: For Surveys Starting after January 01, 2014. Ottawa, ON: Accreditation Canada; 2014.

5. Donovan JL, Drake JA, Whittaker P, Tran MT. Pharmacy-managed anticoagulation: assessment of in-hospital efficacy and evaluation of financial impact and community acceptance. J Thromb Thrombolysis. 2006;22(1):23-30.

6. Dawson NL, Porter IE 2nd, Klipa D, et al. Inpatient warfarin management: pharmacist management using a detailed dosing protocol. J Thromb Thrombolysis. 2012;33(2):178-184.

7. Tschol N, Lai DK, Tilley JA, Wong H, Brown GR. Comparison of physician- and pharmacist-managed warfarin sodium treatment in open heart surgery patients. Can J Cardiol. 2003;19(12):1413-1417.

8. Brice SD. A comparative evaluation of doctor and pharmacist managed inpatient anticoagulation. Pharm Pract. 2001;11(4):134-137.

9. Boddy C. Pharmacist involvement with warfarin dosing for inpatients. Pharm World Sci. 2001;23(1):31-35.

10. Chilipko AA, Norwood DK. Evaluating warfarin management by pharmacists in a community teaching hospital. Consult Pharm. 2014;29(2):95-103.

11. Airee A, Guirguis AB, Mohammad RA. Clinical outcomes and pharmacists' acceptance of a community hospital's anticoagulation management service utilizing decentralized clinical staff pharmacists. Ann Pharmacother. 2009;43(4):621-628.

12. Burns N. Evaluation of warfarin dosing by pharmacists for elderly medical in-patients. Pharm World Sci. 2004;26(4):232-237.

13. Damaske DL, Baird RW. Development and implementation of a pharmacist-managed inpatient warfarin protocol. Proc (Bayl Univ Med Cent). 2005;18(4):397-400.

14. Schillig J, Kaatz S, Hudson M, Krol GD, Szandzik EG, Kalus JS. Clinical and safety impact of an inpatient pharmacist-directed anticoagulation service. J Hosp Med. 2011;6(6):322-328.

15. Hosmane SR, Tucker J, Osman D, Williams S, Waterworth P. Inpatient oral anticoagulation management by clinical pharmacists: safety and cost effectiveness. J Clin Med Res. 2010;2(2):90-92.

16. Rivey MP, Wood RD, Allington DR, Stratton TP, Erickson CC, Stenson TA. Pharmacy-managed protocol for warfarin use in orthopedic surgery patients. Am J Health Syst Pharm. 1995;52(12):1310-1316.

17. Chenella FC, Klotz TA, Gill MA, et al. Comparison of physician and pharmacist management of anticoagulant therapy of inpatients. Am J Hosp Pharm. 1983;40(10):1642-1645.

18. Mamdani MM, Racine E, McCreadie S, et al. Clinical and economic effectiveness of an inpatient anticoagulation service. Pharmacotherapy. 1999;19(9):1064-1074.

19. Bond CA, Raehl CL. Pharmacist-provided anticoagulation management in United States hospitals: Death rates, length of stay, medicare charges, bleeding complications, and transfusions. Pharmacotherapy. 2004;24(8):953-963.
20. Pawloski SJ, Kersh PL. Therapeutic heparin monitoring service in a small community hospital. Hosp Pharm. 1992;27(8):703-723.

21. Saya FG, Coleman LT, Martinoff JT. Pharmacist-directed heparin therapy using a standard dosing and monitoring protocol. Am J Hosp Pharm. 1985;42(9):1965-1969.

22. Hull RD, Raskob GE, Brant RF, Pineo GF, Valentine KA. Relation between the time to achieve the lower limit of the APTT therapeutic range and recurrent venous thromboembolism during heparin treatment for deep vein thrombosis. Arch Intern Med. 1997;157(22):2562-2568.

23. Smith SB, Geske JB, Maguire JM, Zane NA, Carter RE, Morgenthaler TI. Early anticoagulation is associated with reduced mortality for acute pulmonary embolism. Chest. 2010;137(6):1382-1390.

24. Raschke RA, Reilly BM, Guidry JR, Fontana JR, Srinivas S. The weight-based heparin dosing nomogram compared to a "Standard Care" Nomogram: a randomized controlled trial. Ann Intern Med. 1993;119(9):874-881.

25. Cooper T, White CL, Taber D, Uber WE, Kokko H, Mazur J. Safety and effectiveness outcomes of an inpatient collaborative drug therapy management service for direct thrombin inhibitors. Am J Health Syst Pharm. 2012;69(22):1993-1998.

26. To E, Jackevicius C. Quality improvement initiative for pharmacistassisted warfarin dosing: implementation and evaluation of a new protocol. Can J Hosp Pharm. 2002;55(2):105-113.

27. Lobo B, Finch C, Howard-Thompson A, Gillion A. Pharmacist-managed direct thrombin inhibitor protocol improves care of patients with heparin-induced thrombocytopenia. Hosp Pharm. 2010;45(9):705.

28. Ellis RF, Stephens MA, Sharp GB. Evaluation of a pharmacy-managed warfarin-monitoring service to coordinate inpatient and outpatient therapy. Am J Hosp Pharm. 1992;49(2):387-394.

29. Thompson SS, Hannan C, Holden L, Flickinger D. Impact of an inpatient anticoagulation monitoring program. US Pharm. 2012;37(2):HS16-HS22.

30. Wong YM, Quek YN, Tay JC, Chadachan V, Lee HK. Efficacy and safety of a pharmacist-managed inpatient anticoagulation service for warfarin initiation and titration. J Clin Pharm Ther. 2011;36(5):585-591.

31. Dager WE, Gulseth MP. Implementing anticoagulation management by pharmacists in the inpatient setting. Am J Health Syst Pharm. 2007;64(10):1071-1079.

32. Biscup-Horn PJ, Streiff MB, Ulbrich TR, Nesbit TW, Shermock KM. Impact of an inpatient anticoagulation management service on clinical outcomes. Ann Pharmacother. 2008;42(6):777-782.

33. Bauer JB, Chun DS, Karpinski TA. Pharmacist-led program to improve venous thromboembolism prophylaxis in a community hospital. Am J Health Syst Pharm. 2008;65(17):1643-1647.

34. Cronin M, Hill T, Reich D, Pinard B, Krauss ES. Implementation of a multidisciplinary, pharmacy-led, thromboprophylaxis program in total-joint arthroplasty patients. Am J Health Syst Pharm. 2009; 66(2):171-175.
Integrated Pharmacy Research and Practice

\section{Publish your work in this journal}

Integrated Pharmacy Research and Practice is an international, peer-reviewed, open access, online journal, publishing original research, reports, reviews and commentaries on all areas of academic and professional pharmacy practice. This journal aims to represent the academic output of pharmacists and pharmacy practice with particular focus on integrated care. All papers are carefully

\section{Dovepress}

peer reviewed to ensure the highest standards as well as ensuring that we are informing and stimulating pharmaceutical professionals. The manuscript management system is completely online and includes a very quick and fair peer-review system, which is all easy to use. Visit http://www.dovepress.com/ testimonials.php to read real quotes from published authors. 